\title{
Use of Thermal Analysis to predict the conditions for thermal explosion to occur: application to a Ce triethanolamine complex
}

Imen Zghal ${ }^{1,2}$, Jordi Farjas ${ }^{1}$, Jaume Camps ${ }^{1}$, D. Sánchez-Rodríguez ${ }^{1,3}$, Mohamed Dammak $^{2}$, Pere Roura-Grabulosa ${ }^{1}$.

${ }^{1}$ University of Girona, Campus Montilivi, Edif. PII, E17071 Girona, Catalonia, Spain

${ }^{2}$ Laboratoire de Chimie Inorganique, Faculté des Sciences de Sfax, University of Sfax, BP 1171, 3000 Sfax, Tunisia

${ }^{3}$ Department of Materials Science and Biotechnology, Graduate School of Science and Engineering, Ehime University, Matsuyama 790-8577, Japan

\begin{abstract}
In this contribution we show that thermal analysis is useful to analyze the ignition condition for a system to undergo a thermal runaway. First, thermal analysis provides the tools to determine the parameters that control the ignition condition. Second, thermal analysis allows us to identify the occurrence of a thermal runaway as well as to monitor its evolution. For this purpose, we apply thermal analysis to predict and analyze the occurrence of a thermal runaway in a cerium triethanolamine complex.
\end{abstract}

Keywords: Thermal Analysis, Thermal explosion, Combustion, Thermal Runaway, Ignition condition.

*Corresponding author: jordi.farjas@udg.edu, Tel (34)972418490, Fax (34) 972418098

University of Girona, Campus Montilivi, Edif. PII, E17071 Girona, Catalonia, Spain 


\section{Introduction}

The prediction of the occurrence of a thermal runaway, i.e., the formation of a combustion zone that propagates at high speed, is of utmost importance for a number of applications [1] such as evaluating the chemical risk and preventing ignition in chemical reactors or during the storage and transportation of hazardous materials [2-7], determining the conditions for pyrotechnic reactions to happen [8-10], determining munitions cookoff temperatures [11] and, in general, establishing the ignition condition in chemical engineering processes $[12,13]$. It is also important for intermetallic reactions and thermites (metal-metal oxides mixtures) that are used in some pyrotechnic devices such as igniters [14].

Moreover, combustion synthesis is an efficient and cost-competitive processing technique that takes advantage of the heat evolved during the chemical reaction of precursor substances to obtain materials that otherwise would require achieving hightemperatures [15]. Indeed, combustion has become a very versatile route for the synthesis of intermetallic or oxide powders and compacts [15-20]. Combustion of bimetallic foils is used to join temperature-sensitive or dissimilar materials [21,22]. More recently, combustion synthesis of functional oxides from precursor salts (nitrates or metalorganic precursors) has attracted much attention due to the growing interest in these materials [23]. Also, nanoscale oxides, metals, alloys, and sulfides have been obtained from an aqueous or sol-gel media based on the so-called solution combustion synthesis [24].

The occurrence of a thermal runaway is controlled by two competing phenomena: the exothermic reaction that tends to increase the local temperature, and heat dissipation that lowers the temperature through heat transfer towards the container walls [1]. Any combustion process must be initiated by a so-called "ignition" event. Ignition produces a localized overheating that will propagate as a combustion front along the volume of the material. Two different igniting modes are usually considered in the literature $[17,18,25]$. In the "self-propagating high temperature" mode, ignition is created locally by an external and localized energy source (a spark, a laser beam, an electrical discharge, etc) [20,21]. In the "thermal explosion" (also known as "volumetric") mode, the reactants are heated to a temperature where the reaction becomes locally unstable [26].

Frank-Kamenetskii and Semenov [27,28] derived the critical condition for thermal explosion in homogeneous system with a very simple geometry assuming that the activation energy is infinite and neglecting reactant consumption. Several authors have 
developed more accurate solutions that account for reactant consumption and finite activation energies [27,29-37].

The critical condition depends on the temperature of the crucible walls and the following system parameters: activation energy, pre-exponential term of the kinetic constant, thermal conductivity, thermal capacity, density and reaction enthalpy. As we will show in this communication, all these parameters but the density can be determined using thermal analysis (TA) methods. In particular, we will determine the parameters of a cerium triethanolamine (TEA), Ce-TEA, complex. In this complex, TEA is a reducing agent that acts as fuel while the nitrate group is a strong oxidizer. So Ce-TEA contains both the fuel and the oxidizer and undergoes combustion in the usual conditions used in TA measurements [38-41].

Recently, a critical condition has been derived that also takes into account realistic geometries [42] and constant heating conditions [43]. Therefore, it is possible to know the conditions for a thermal runaway to occur in a TA measurement under isothermal and constant heating conditions. The latter is of especial interest because constant heating measurements are easier and faster to perform in TA [44]. Therefore, we will be able to check the validity of the critical condition obtained for $\mathrm{Ce}-\mathrm{TEA}$ complex and for different crucible sizes and heating rates.

\section{Materials and methods}

\subsection{Preparation of Ce-TEA complex}

Ce-TEA was prepared according the procedure described in $[38,39] ; 10.86 \mathrm{~g}$ Cerium(III) nitrate hexahydrate $\left(\mathrm{Ce}\left(\mathrm{NO}_{3}\right)_{3} \cdot 6 \mathrm{H}_{2} \mathrm{O}\right.$ Alfa Aesar $\left.\geq 99.5 \%\right)$ was dissolved into $200 \mathrm{ml} \mathrm{1-propanol} \mathrm{(VWR,} \geq 99.9 \%$ ) in a round bottom flask under nitrogen at $60^{\circ} \mathrm{C}$ using a stirring magnetic hot plate. When a clear solution was obtained, the heating system was shut down. Simultaneously, a mixture of $7.472 \mathrm{~g}$ of TEA $\left(\mathrm{C}_{6} \mathrm{H}_{15} \mathrm{NO}_{3}\right.$, Merck, $\left.\geq 99 \%\right)$ and $100 \mathrm{ml}$ of $1-$ propanol was added to the warm cerium nitrate solution. This mixture was stirred under nitrogen for 30 minutes. The mixture was filtered and the resulting crystals were washed successively in ethanol and acetone. Finally, the crystals were dried at room temperature in vacuum.

From X-ray diffraction, elemental analysis and infrared analysis, Ce-TEA has been identified as the $\mathrm{Ce}(\mathrm{III})$ complex: $\left[\mathrm{Ce}\left(\mathrm{NO}_{3}\right)\left(\mathrm{C}_{6} \mathrm{H}_{15} \mathrm{NO}_{3}\right)_{2}\right]\left(\mathrm{NO}_{3}\right)_{2}$ [38]. So in the $\mathrm{Ce}-\mathrm{TEA}$ complex we have two TEA molecules and three nitrate groups per cerium atom. 
Thus, Ce-TEA contains both the fuel and the oxidizer, and experiences combustion in both inert and oxidizing atmospheres; i.e. no oxygen is needed to sustain combustion.

\subsection{Characterization techniques}

Simultaneous thermogravimetric (TG) and Differential Scanning Calorimetry (DSC) analyses has been performed in a Mettler Toledo thermo-balance, model TGA/DSC1, at $10 \mathrm{~K} / \mathrm{min}$ under a gas flow of $40 \mathrm{ml} / \mathrm{min}$ of high purity $\mathrm{N}_{2}$ or synthetic air. Uncovered $\mathrm{Al}_{2} \mathrm{O}_{3}$ crucibles of 70 and $150 \mu \mathrm{l}$ were used. DSC analysis has been carried out in a Mettler Toledo DSC822e; samples were placed in either in open $70 \mu 1$-alumina crucibles, or in $20 \mu \mathrm{l}$ aluminum crucibles covered with a pinned lid to allow for gas exchange. DSC measurements were done under a constant heating rate of $10 \mathrm{~K} / \mathrm{min}$ and under a gas flow of $40 \mathrm{ml} / \mathrm{min}$ of high purity $\mathrm{N}_{2}$.

\section{Determination of the material's parameters}

The values of the measured material's parameters are summarized in Table 1 . The density was determined using a vessel of known volume and filling it with powders in the same way we use to fill the crucibles in the TG experiments: with the powder inside, the crucible was gently tapped against a solid horizontal surface The rest of parameters were determined using TA. In the following, we describe the methodology and the results.

\subsection{Determination of the kinetic parameters}

We have used isoconversional methods to determine the apparent activation energy and the pre-exponential term because there is a general consensus that they are among the most reliable ones and they are model-free [45-48]; no assumptions about the reaction model is to be made. Isoconversional methods rely on the assumption that at a given degree of transformation, $\alpha$, the transformation rate is only a function of the temperature,

$$
\left[\frac{d \ln (d \alpha / d t)}{d T^{-1}}\right]_{\alpha}=-\frac{E_{\alpha}}{R_{G}},
$$

where $T$ is the temperature, $E_{\alpha}$ is the apparent activation energy at a particular $\alpha$ value and $R_{G}$ is the gas constant. From integration of Eq. (1) we obtain,

$$
\frac{d \alpha}{d t}=A_{\alpha} \exp \left[-\frac{E_{\alpha}}{R_{G} T}\right] f(\alpha) \text {. }
$$


Note that the kinetic parameters, activation energy $E_{\alpha}$ and the pre-expenential term $A_{\alpha} f(\alpha)$, are not constant but depend on the degree of transformation.

To determine the kinetic parameters, at least three experiments have to be performed at different temperatures (isothermal) or at different constant heating rates,

$\beta \equiv \frac{d T}{d t}=$ constant (non-isothermal). Because non-isothermal experiments are faster and easier to perform, we have measured the thermal decomposition of Ce-TEA when heated at $\beta=2.5,5$ and $10 \mathrm{~K} / \mathrm{min}$ in $\mathrm{N}_{2}$ flowing gas. The results are shown in Fig. 1. To properly determine the kinetic parameters, it is necessary to avoid the event of a thermal runaway. For this reason, we have chosen an initial mass of $5.2 \mathrm{mg}$ for the three experiments. Moreover, from Fig 1, it is apparent that the decomposition of Ce-TEA is a complex process. Two main stages have been identified [38]: a fast one that ends around $300^{\circ} \mathrm{C}$ (note the elbow at the TG curve) and a slow one that extends up to $800^{\circ} \mathrm{C}$ and beyond. Since combustion occurs at the first stage, we have limited our kinetic analysis to this stage; in Fig 2 we have plotted the $\alpha(\mathrm{T})$ curves obtained from the TG curves of Fig 1 assuming that: i) initially $\alpha=0$, ii) at the end of this first stage $\alpha=1$, and iii) the transformation rate is proportional to the mass-loss rate.

We have used different isoconversional methods to determine the kinetic parameters: Friedman [49], Vyazovkin [50], Li and Tang [51,52] and Ortega's exact method [45,53], the result is plotted in the inset of Fig. 2. All methods deliver very similar results, but the activation energy is not constant. Nevertheless, the thermal runaway starts when the degree of transformation is approximately 0.3 . Up to $\alpha=0.3$, the activation energy is approximately constant. So, to calculate the critical condition, we have assumed a constant activation energy of $220 \mathrm{~kJ} / \mathrm{mol}$ and a pre-exponential term $A=2.34 \times 10^{19} \mathrm{~s}^{-1}$.

\subsection{Thermal Conductivity}

Thermal conductivity of Ce-TEA powder was obtained from the slope of the DSC melting peak of indium according to the method developed in refs. [54,55]. The method is based on the slope of the low temperature side of the melting peak of a reference metal bead placed on the top of an amount of powder that fills a cylindrical crucible (Fig.3), when heated at a constant rate. This slope depends on the powder thermal resistance, $R P$, and the DSC and contact crucible to sensor thermal resistances ( $R_{S}$ and $R_{C}$, respectively) according to: 


$$
S_{P}=\frac{1}{R_{S}+R_{C}+R_{P}}
$$

$R_{S}+R_{C}$ can be obtained if one measures the slope of the melting peak without the powder (Fig.3) and with a metal bead blasted inside the crucible bottom to ensure good thermal contact:

$$
S_{e}=\frac{1}{R_{S}+R_{C}}
$$

Once the thermal resistance $R_{P}$ is known, the thermal conductivity is given by,

$$
\lambda=\frac{K}{\pi R_{P}}\left[\frac{1}{D_{m}}-\frac{1}{D_{p}}\right]
$$

where $D_{m}$ is the diameter of the metal bead, $D_{p}$ is the internal diameter of the cylindrical crucible and $K$ is a geometrical factor that depends on the ratio $D_{m} / D_{p}$ and on the ratio between the crucible height $h$ and $D_{p}$. For most commercial crucibles $K$ is very close to unity [54].

Since the melting point of Ce-TEA is in the temperature range of the measurement, before measuring the thermal conductivity the precursor is melt and quenched so an amorphous phase appears and no melting event occurs during the measurement. Experiments were conducted in a $40 \mathrm{ml} / \mathrm{min}$ nitrogen flow and a heating rate of $10 \mathrm{~K} / \mathrm{min}$ in the temperature range $50-200^{\circ} \mathrm{C}$. For an indium bead of $D_{m}=2.00$ $\mathrm{mm}$ and a crucible of $D_{P}=4.95$ and $h=0.7 \mathrm{~mm}(K=1.05)$ we obtained $S_{P}=0.806$ and $S_{e}=15.66 \mathrm{~mW} / \mathrm{K}$ that deliver a thermal conductivity $\lambda=0.0846 \mathrm{~W} /(\mathrm{K} \cdot \mathrm{m})$ (Fig.3). Note, that the thermal conductivity of Ce-TEA is very low. This low thermal conductivity reduces significantly thermal dissipation and thus facilitates the formation of temperature gradients inside the sample $[56,57]$ and the occurrence of a thermal runaway $[58,59]$.

\subsection{Specific heat capacity}

When a sample is heated at a constant rate, the DSC signal is proportional to the heating rate,

$$
D S C=-c m \beta,
$$

where $c$ is the specific heat capacity and $m$ is the sample mass. Since any apparatus has a non-zero baseline, this baseline has to be subtracted. Unfortunately, this baseline is not reproducible and this lack of reproducibility is worse when the furnace is opened. Thus a strategy has to be applied to remove the effect of the baseline. We have used a method 
that consists of consecutive isothermal and non-isothermal measurements [60]. The jump in the DSC signal between the isotherm and the non-isotherm steps, $\triangle D S C$, is:

$$
\triangle D S C=-c m \beta .
$$

Due to the apparatus and sample thermal inertia, there is a transient period between isothermal to non-isothermal steps. For this reason, the duration of every thermal segment was $4 \mathrm{~min}$ to allow for the system to stabilize. The heating rate was $10 \mathrm{~K} / \mathrm{min}$; so, the temperature difference between two consecutive isotherms was $40{ }^{\circ} \mathrm{C}$. We measured the heat capacity at 100,140 and $180^{\circ} \mathrm{C}$. In addition, we performed the experiment twice; first with a substance of known heat capacity to calibrate the DSC signal and afterwards with $\mathrm{Ce}$-TEA powder. For the calibration we used $\mathrm{Al}_{2} \mathrm{O}_{3}$ powders. The measurement performed on Ce-TEA powder is shown in Fig. 4. From Fig. 4 one can observe the transient behavior after any change of heating rate. So, to determine the heat capacity at the selected temperatures it is necessary to extrapolate the DSC signal (dashed lines in Fig. 4) to the time when the heating rate changes. Finally, since the heat capacity of reference and sample crucibles is not perfectly balanced, there is a reproducible DSC signal jump that needs to be corrected. This effect can be subtracted by running a "blank" experiment under the same conditions but with empty crucibles. This blank experiment is shown in the top of Fig. 4. Following this method, the heat capacities of Ce-TEA at 100,140 and $180^{\circ} \mathrm{C}$ have been determined to be 866,950 and $1010 \mathrm{~J} /(\mathrm{kg} \cdot \mathrm{K})$, respectively. To determine the critical condition, we have chosen the closest value to the combustion temperature, $c=1010 \mathrm{~J} /(\mathrm{kg} \cdot \mathrm{K})$.

\subsection{Reaction enthalpy}

It is of no use to measure the exact reaction enthalpy of the reaction because part of the heat released by the reaction is carried away by the volatile components [61], thus it does not contribute to the increase in the sample temperature. Therefore, parameter $q$ is determined directly from the integration of the DSC signal during the decomposition, since it corresponds to the sample overheating resulting from the heat released by the chemical reaction.

\section{Critical condition under constant heating rate}


The evolution of the thermal decomposition of Ce-TEA for different initial sample masses is shown in Fig. 5. Above a critical value of the sample mass (around $8 \mathrm{mg}$ ) the evolution is characterized by a discontinuity in the first derivative of the mass evolution, a sudden drop of the sample mass and a sharp exothermic peak (not shown). This features are characteristic of a thermal runaway $[43,62,63]$. In the case of exothermic reactions, the sample undergoes a thermal runaway when the time to dissipate the heat generated by the reaction is larger than the characteristic reaction time. The time needed to dissipate the heat increases with the system size, so larger sample are more prone to undergo a thermal runaway. In particular, for powder inside a cylindrical crucible of radius $R$ filled up to a height $H$ and heated at a constant rate $\beta$, the critical mass $\left(m_{c r}\right)$ is given by [43]:

$$
m_{c r}=\frac{5 \pi a \rho}{\gamma} \frac{0.878 R^{2}+2 H^{2}}{H} .
$$

where $a$ is the thermal diffusivity $(a \equiv \lambda / \rho c)$ and,

$$
\begin{gathered}
\gamma=A \theta_{T}(1+2 \varepsilon)\left\{1-\left(2+\varepsilon+30 \varepsilon^{2}\right) \frac{2}{\theta_{T}}\right\} e^{-1 / \varepsilon} \\
\theta_{T}=\frac{E_{A}}{R_{G} T_{K i s}^{2}} \frac{q}{c}, \varepsilon=\frac{R_{G} T_{K i s}}{E_{A}}
\end{gathered}
$$

and $T_{K i s}$ is the temperature at which the reaction rate is at its maximum. It can be calculated from the Kissinger equation [64-66]:

$$
\frac{E_{A}}{R_{G} T_{\text {Kis }}^{2}}=\frac{A}{\beta} \exp \left[-\frac{E_{A}}{R_{G} T_{K i S}}\right] \text {. }
$$

Taking into account that $m=\pi \rho R^{2} H$, Eq. 8 can be expressed as,

$$
\frac{\gamma}{5 a}=\frac{0.878}{H^{2}}+\frac{2}{R^{2}} \text {. }
$$

Thus, if the radius $R$ is known, Eq. 11 can be solved for $H$ and, therefore, we can calculate $m_{c r}$ as a function of the crucible radius;

$$
m_{c r}=\pi \rho R^{3} \sqrt{0.878\left(\frac{\gamma R^{2}}{5 a}-2\right)^{-1}}
$$

Therefore, from the physical parameters discussed in the previous sections, that are summarized in Table 1, we have calculated the critical mass, $m_{c r}$, for powder heated at $10 \mathrm{~K} / \mathrm{min}$ inside a $150 \mu \mathrm{l}$ alumina crucible (radius $R=3.5 \mathrm{~mm}$ ). We have obtained a critical mass of $7.99 \mathrm{mg}$ which is in agreement with Fig. 5; a sample mass of $8.03 \mathrm{mg}$ undergoes combustion while the sample of mass of $7.14 \mathrm{mg}$ exhibits a smooth evolution. 
To check the validity of Eq. 12 we have determined the critical mass from several sets of experiments performed at different heating rates $(2.5,5$ and $10 \mathrm{~K} / \mathrm{min})$ on $150 \mu 1$ alumina crucibles, and one set of experiments done at $10 \mathrm{~K} / \mathrm{min}$ for a $70 \mu \mathrm{l}$ alumina crucible (radius $R=2.3 \mathrm{~mm}$ ), all of them under an air flow of $40 \mathrm{ml} / \mathrm{min}$. The results are summarized in Fig. 6. The experimental critical mass is between the empty symbols (no combustion) and full symbols (combustion). In addition, we have plotted (lines) the prediction delivered by Eq. 12 . One can verify that there is a nice agreement between the experimental results and the theoretical prediction. Furthermore, one can verify that the critical mass diminishes when the parameter $\gamma / a$ increases. In other words, to promote combustion we need low thermal diffusivities and large values of Todes parameter $\theta_{T}$ (low thermal capacities and high enthalpies). Finally, from Fig. 6, it is apparent that the higher the heating rate the easier to set a thermal runaway.

\section{Conclusions}

We have shown that Thermal Analysis methods are powerful tools to analyze thermal explosion. First, they provide the techniques to determine the material's parameters that control the occurrence of a thermal runaway: kinetic parameters, thermal conductivity, specific heat capacity and specific reaction enthalpy.

Second, when the thermal conductivity is low thermal explosion can occur during Thermal Analysis measurements. In this case, it is possible to determine the thermal explosion threshold under different conditions (crucible diameter and heating rate) by TG.

The decomposition of Ce-TEA complex has been used to illustrate how to proceed to predict and determine the critical mass for thermal explosion to occur. Very good agreement between theory and experiment has been achieved.

\section{Acknowledgements}

This work was funded by Ministerio de Ciencia, Innovación y Universidades (grant number RTI2018-095853-B-C22) and by the Generalitat of Catalunya (2017-SGR-1519). 


\section{References}

[1] A.G. Merzhanov, B.I. Khaikin, Theory of combustion waves in homogeneous media, Prog. Energy Combust. Sci. 14 (1988) 1-98. doi:10.1016/03601285(88)90006-8.

[2] J. Adler, J.W. Enig, The critical conditions in thermal explosion theory with reactant consumption, Combust. Flame. 8 (1964) 97-103. doi:10.1016/00102180(64)90035-5.

[3] J.M. Zaldívar, J. Cano, M.A. Alós, J. Sempere, R. Nomen, D. Lister, G. Maschio, T. Obertopp, E.D. Gilles, J. Bosch, F. Strozzi, A general criterion to define runaway limits in chemical reactors, J. Loss Prev. Process Ind. 16 (2003) 187200. doi:10.1016/S0950-4230(03)00003-2.

[4] B. Roduit, L. Xia, P. Folly, B. Berger, J. Mathieu, A. Sarbach, H. Andres, M. Ramin, B. Vogelsanger, D. Spitzer, H. Moulard, D. Dilhan, The simulation of the thermal behavior of energetic materials based on DSC and HFC signals, J. Therm. Anal. Calorim. 93 (2008) 143-152. doi:10.1007/s10973-007-8864-3.

[5] G. Krause, Volume-Dependent Self-Ignition Temperatures for Explosive Materials, Propellants, Explos. Pyrotech. 37 (2012) 107-115. doi:10.1002/prep.201100007.

[6] B. Roduit, M. Hartmann, P. Folly, A. Sarbach, P. Brodard, R. Baltensperger, Determination of thermal hazard from DSC measurements. Investigation of selfaccelerating decomposition temperature (SADT) of AIBN, J. Therm. Anal. Calorim. 117 (2014) 1017-1026. doi:10.1007/s10973-014-3903-3.

[7] M. Dellavedova, C. Pasturenzi, L. Gigante, A. Lunghi, Kinetic Evaluations for the Transportation of Dangerous Chemical Compounds, Chem. Eng. Trans. 26 (2012) 585-590. doi:10.3303/CET1226098.

[8] T. Boddington, A. Cottrell, P.G. Laye, A numerical model of combustion in gasless pyrotechnic systems, Combust. Flame. 76 (1989) 63-69. doi:10.1016/0010-2180(89)90078-3.

[9] J. Zinn, C.L. Mader, Thermal Initiation of Explosives, J. Appl. Phys. 31 (1960) 323. doi:10.1063/1.1735565.

[10] R.N. Rogers, Thermochemistry of explosives, Thermochim. Acta. 11 (1975) 131-139. doi:10.1016/0040-6031(75)80016-5.

[11] A.C. Victor, Simple Calculation Methods for Munitions Cookoff times and 
temperatures, Propellants, Explos. Pyrotech. 20 (1995) 252-259.

doi:10.1002/prep.19950200506.

[12] T. Kotoyori, Critical Temperatures for the Thermal Explosion of Chemicals, 1st ed., Elsevier, Amsterdam, 2005. doi:10.1016/S0921-9110(05)80003-5.

[13] J.F. Griffiths, J.A. Barnard, Flame and Combustion, 3rd ed., CRC Press, London, 1995.

[14] P.V. Phung, A.P. Hardt, Ignition characteristics of gasless reactions, Combust. Flame. 22 (1974) 323-335. doi:10.1016/0010-2180(74)90047-9.

[15] K. Morsi, The diversity of combustion synthesis processing: a review, J. Mater. Sci. 47 (2011) 68-92. doi:10.1007/s10853-011-5926-5.

[16] J.J. Moore, H.J. Feng, Combustion synthesis of advanced materials: Part I. Reaction parameters, Prog. Mater. Sci. 39 (1995) 243-273. doi:10.1016/00796425(94)00011-5.

[17] A. Varma, A.S. Rogachev, A.S. Mukasyan, S. Hwang, Combustion Synthesis of Advanced Materials: Principles and Applications, Adv. Chem. Eng. 24 (1998) 79-226. doi:10.1016/S0065-2377(08)60093-9.

[18] K.C. Patil, S.T. Aruna, T. Mimani, Combustion synthesis: an update, Curr. Opin. Solid State Mater. Sci. 6 (2002) 507-512. doi:10.1016/S1359-0286(02)00123-7.

[19] P. Mossino, Some aspects in self-propagating high-temperature synthesis, Ceram. Int. 30 (2004) 311-332. doi:10.1016/S0272-8842(03)00119-6.

[20] C.-L. Yeh, Combustion Synthesis: Principles and Applications, in: K.H.J. Buschow, R.W. Cahn, M.C. Flemings, B. Ilschner, E.J. Kramer, S. Mahajan, P. Veyssière (Eds.), Encycl. Mater. Sci. Technol., 2nd ed., Elsevier, Oxford, 2010: pp. 1-8. doi:10.1016/B978-008043152-9.02217-X.

[21] R. V Reeves, M.A. Rodriguez, E.D. Jones, D.P. Adams, Condensed-Phase and Oxidation Reaction Behavior of Ti/2B Foils in Varied Gaseous Environments, J. Phys. Chem. C. 116 (2012) 17904-17912. doi:10.1021/jp303785r.

[22] J. Wang, E. Besnoin, O.M. Knio, T.P. Weihs, Effects of physical properties of components on reactive nanolayer joining, J. Appl. Phys. 97 (2005) 114307. doi:10.1063/1.1915540.

[23] T. Striker, J.A. Ruud, Effect of Fuel Choice on the Aqueous Combustion Synthesis of Lanthanum Ferrite and Lanthanum Manganite, J. Am. Ceram. Soc. 93 (2010) 2622-2629. doi:10.1111/j.1551-2916.2010.03799.x.

[24] A. Varma, A.S. Mukasyan, A.S. Rogachev, K. V. Manukyan, Solution 
Combustion Synthesis of Nanoscale Materials, Chem. Rev. 116 (2016) 1449314586. doi:10.1021/acs.chemrev.6b00279.

[25] O.S. Rabinovich, P.S. Grinchuk, M.A. Andreev, B.B. Khina, Conditions for combustion synthesis in nanosized Ni/Al films on a substrate, Phys. B Condens. Matter. 392 (2007) 272-280. doi:10.1016/j.physb.2006.11.032.

[26] L. Thiers, A.S. Mukasyan, A. Varma, Thermal explosion in Ni-Al system: influence of reaction medium microstructure, Combust. Flame. 131 (2002) 198209. doi:10.1016/S0010-2180(02)00402-9.

[27] D.A. Frank-Kamenetskii, Diffusion and Heat Exchange in Chemical Kinetics, 2nd ed., Princeton University Press, New Jersey, 1955.

[28] N. Semenov, Thermal Theory of Combustion and Explosion, Prog. Phys. Sci. USSR. 23 (1940) 251-292. http://hdl.handle.net/2060/20030065137.

[29] D.R. Kassoy, A. Liñan, The influence of reactant consumption on the critical conditions for homogeneous thermal explosions, Q. J. Mech. Appl. Math. 31 (1978) 99-112. doi:10.1093/qjmam/31.1.99.

[30] P. Gray, M.J. Harper, Thermal explosions. Part 1.-Induction periods and temperature changes before spontaneous ignition, Trans. Faraday Soc. 55 (1959) 581-590. doi:10.1039/tf9595500581.

[31] O.M. Todes, P. V Melentjew, The theory of heat explosion II Heat explosion for mono-molecular reactions, Acta Physicochim. URSS. 11 (1939) 153-180.

[32] W. Squire, A mathematical analysis of self-ignition, Combust. Flame. 7 (1963) 1-8. doi:10.1016/0010-2180(63)90150-0.

[33] P. Gray, P.R. Lee, Thermal explosions and the effect of reactant consumption on critical conditions, Combust. Flame. 9 (1965) 201-203. doi:10.1016/00102180(65)90068-4.

[34] A.A. Lacey, Critical behaviour of homogeneous reacting systems with large activation energy, Int. J. Eng. Sci. 21 (1983) 501-515. doi:10.1016/00207225(83)90098-8.

[35] V.I. Babushok, V.M. Goldshtein, V.A. Sobolev, Critical Conditions for Thermal Explosion with Reactant Consumption, Combust. Sci. Technol. 70 (1990) 81-89. doi:10.1080/00102209008951613.

[36] P.H. Thomas, Effect of Reactant Consumption on the Induction Period and Critical Condition for a Thermal Explosion, Proc. R. Soc. A Math. Phys. Eng. Sci. 262 (1961) 192-206. doi:10.1098/rspa.1961.0112. 
[37] M. Morbidelli, A. Varma, A generalized criterion for parametric sensitivity: Application to thermal explosion theory, Chem. Eng. Sci. 43 (1988) 91-102. doi:10.1016/0009-2509(88)87129-X.

[38] I. Zghal, J. Farjas, J. Camps, M. Dammak, P. Roura-Grabulosa, Thermal decomposition of cerium triethanolamine complexes, Accepted in Thermochimica Acta.

[39] H. İçbudak, V.T. Yilmaz, H. Ölmez, Thermal decomposition behaviour of some trivalent transition and inner-transition metal complexes of triethanolamine, Thermochim. Acta. 289 (1996) 23-32. doi:10.1016/S0040-6031(96)03041-9.

[40] W. Wattanathana, A. Lakkham, A. Kaewvilai, N. Koonsaeng, A. Laobuthee, C. Veranitisagul, Preliminary Study of $\mathrm{Pd} / \mathrm{CeO} 2$ Derived from Cerium Complexes as Solid Support Catalysts for Hydrogenation Reaction in a Micro-reactor, Energy Procedia. 9 (2011) 568-574. doi:10.1016/j.egypro.2011.09.066.

[41] D. Sánchez-Rodríguez, S. Yamaguchi, D. Ihara, H. Yamaura, H. Yahiro, Selfpropagating high-temperature synthesis of highly dispersed noble metals on ceria powder: Application to Pd/CeO 2 catalyst, Ceram. Int. 43 (2017) 14533-14536. doi:10.1016/j.ceramint.2017.07.208.

[42] D. Sánchez-Rodriguez, J. Farjas, P. Roura, The Critical Condition for Thermal Explosion in an Isoperibolic System, AIChE J. (2017). doi:10.1002/aic.15727.

[43] D. Sánchez-Rodriguez, J. Farjas, P. Roura, The critical conditions for thermal explosion in a system heated at a constant rate, Combust. Flame. 186 (2017) 211-219. doi:10.1016/j.combustflame.2017.08.008.

[44] S. Vyazovkin, C.A. Wight, Kinetics in solids., Annu. Rev. Phys. Chem. 48 (1997) 125-49. doi:10.1146/annurev.physchem.48.1.125.

[45] J. Farjas, P. Roura, Isoconversional analysis of solid state transformations. A critical review. Part I. Single step transformations with constant activation energy, J. Therm. Anal. Calorim. 105 (2011) 757-766. doi:10.1007/s10973-011$1446-4$

[46] J. Farjas, P. Roura, Isoconversional analysis of solid state transformations. A critical review. Part II. Complex transformations, J. Therm. Anal. Calorim. 105 (2011) 767-773. doi:10.1007/s10973-011-1447-3.

[47] M.E. Brown, M. Maciejewski, S. Vyazovkin, R. Nomen, J. Sempere, A. Burnham, J. Opfermann, R. Strey, H.L. Anderson, A. Kemmler, R. Keuleers, J. Janssens, H.O. Desseyn, C.-R. Li, T.B. Tang, B. Roduit, J. Malek, T. Mitsuhashi, 
Computational aspects of kinetic analysis: Part A: The ICTAC kinetics projectdata, methods and results, Thermochim. Acta. 355 (2000) 125-143. doi:10.1016/S0040-6031(00)00443-3.

[48] S. Vyazovkin, A.K. Burnham, J.M. Criado, L.A. Pérez-maqueda, C. Popescu, N. Sbirrazzuoli, ICTAC Kinetics Committee recommendations for performing kinetic computations on thermal analysis data, Thermochim. Acta. 520 (2011) 119. doi:10.1016/j.tca.2011.03.034.

[49] H.L. Friedman, Kinetics of thermal degradation of char-forming plastics from thermogravimetry. Application to a phenolic plastic, J. Polym. Sci. Part C Polym. Symp. 6 (1964) 183-195. doi:10.1002/polc.5070060121.

[50] S. Vyazovkin, Modification of the integral isoconversional method to account for variation in the activation energy, J. Comput. Chem. 22 (2001) 178-183. doi:10.1002/1096-987X.

[51] C.-R. Li, T.B. Tang, A new method for analysing non-isothermal thermoanalytical data from solid-state reactions, Thermochim. Acta. 325 (1999) 43-46. doi:10.1016/S0040-6031(98)00568-1.

[52] C.-R. Li, T.B. Tang, Dynamic thermal analysis of solid-state reactions, J. Therm. Anal. 49 (1997) 1243-1248. doi:10.1007/BF01983680.

[53] A. Ortega, A simple and precise linear integral method for isoconversional data, Thermochim. Acta. 474 (2008) 81-86. doi:10.1016/j.tca.2008.05.003.

[54] M. Pujula, D. Sánchez-Rodríguez, J.P. Lopez-Olmedo, J. Farjas, P. Roura, Measuring thermal conductivity of powders with differential scanning calorimetry, J. Therm. Anal. Calorim. 125 (2016) 571-577. doi:10.1007/s10973016-5274-4.

[55] D. Sánchez-Rodríguez, J.P. López-Olmedo, J. Farjas, P. Roura, Determination of thermal conductivity of powders in different atmospheres by differential scanning calorimetry, J. Therm. Anal. Calorim. 121 (2015) 469-473. doi:10.1007/s10973015-4429-z.

[56] D. Sánchez-Rodríguez, H. Eloussifi, J. Farjas, P. Roura, M. Dammak, Thermal gradients in thermal analysis experiments: Criterions to prevent inaccuracies when determining sample temperature and kinetic parameters, Thermochim. Acta. 589 (2014) 37-46. doi:10.1016/j.tca.2014.05.001.

[57] J. Farjas, D. Sánchez-Rodriguez, H. Eloussifi, P. Roura, Thermal Gradients in Thermal Analysis Experiments, in: J. Šesták, P. Hubík, J.J. Mareš (Eds.), Therm. 
Phys. Therm. Anal. From Macro to Micro, Highlighting Thermodyn. Kinet. Nanomater., Budapest, 2017: pp. 345-362. doi:10.1007/978-3-319-45899-1_16.

[58] A.S. Mukasyan, A.S. Rogachev, Discrete reaction waves: Gasless combustion of solid powder mixtures, Prog. Energy Combust. Sci. 34 (2008) 377-416. doi:10.1016/j.pecs.2007.09.002.

[59] D. Sánchez-Rodríguez, H. Wada, S. Yamaguchi, J. Farjas, H. Yahiro, Synthesis of $\mathrm{LaFeO} 3$ perovskite-type oxide via solid-state combustion of a cyano complex precursor: The effect of oxygen diffusion, Ceram. Int. 43 (2017) 3156-3165. doi:10.1016/j.ceramint.2016.11.134.

[60] P. Roura, D. Sanchez-Rodriguez, J. Farjas, Measurement by differential scanning calorimetry of specific heat capacity variation due to crystallization: Application to amorphous silicon, Thermochim. Acta. 522 (2011) 161-165. doi:10.1016/j.tca.2011.02.014.

[61] E. García, D. Sánchez-Rodríguez, J.P. López-Olmedo, J. Farjas, P. Roura, The effect of volatiles on the measurement of the reaction heat by differential scanning calorimetry, J. Therm. Anal. Calorim. (2015) 187-194. doi:10.1007/s10973-015-4465-8.

[62] D. Sánchez-Rodriguez, J. Farjas, P. Roura, The critical condition for thermal explosion in an isoperibolic system, AIChE J. 63 (2017) 3979-3993. doi:10.1002/aic.15727.

[63] A.G. Merzhanov, V.V. Barzykin, A.S. Shteinberg, V.T. Gontkovskaya, Methodological Principles in studying chemical reaction kinetics under conditions of programmed heating, Thermochim. Acta. 21 (1977) 301-332. doi:10.1016/0040-6031(77)85001-6.

[64] H.E. Kissinger, Reaction Kinetics in Differential Thermal Analysis, Anal. Chem. 29 (1957) 1702-1706. doi:10.1021/ac60131a045.

[65] P. Roura, J. Farjas, Analytical solution for the Kissinger equation, J. Mater. Res. 24 (2009) 3095-3098. doi:10.1557/jmr.2009.0366.

[66] J. Farjas, P. Roura, Exact analytical solution for the Kissinger equation: Determination of the peak temperature and general properties of thermally activated transformations, Thermochim. Acta. 598 (2014) 51-58. doi:10.1016/j.tca.2014.10.024. 
Table 1. Physical Parameters of $\left[\mathrm{Ce}\left(\mathrm{NO}_{3}\right)\left(\mathrm{C}_{6} \mathrm{H}_{15} \mathrm{NO}_{3}\right)_{2}\right]\left(\mathrm{NO}_{3}\right)_{2}$, $\mathrm{Ce}-\mathrm{TEA}$.

\begin{tabular}{ll}
\hline \hline Activation Energy, $E_{A}[\mathrm{~kJ} / \mathrm{mol}]$ & 220 \\
Pre-exponential term, $A\left[\mathrm{~s}^{-1}\right]$ & $2.34 \times 10^{19}$ \\
Enthalpy of reaction, $q[\mathrm{~J} / \mathrm{kg}]$ & $3.74 \times 10^{6}$ \\
Apparent density, $\rho\left[\mathrm{kg} / \mathrm{m}^{3}\right]$ & 578 \\
Thermal Conductivity, $\lambda[\mathrm{W} /(\mathrm{m} \cdot \mathrm{K})]$ & 0.0846 \\
Specific heat capacity, $c[\mathrm{~J} /(\mathrm{kg} \cdot \mathrm{K})]$ & $1010\left(180^{\circ} \mathrm{C}\right)$ \\
\hline \hline
\end{tabular}




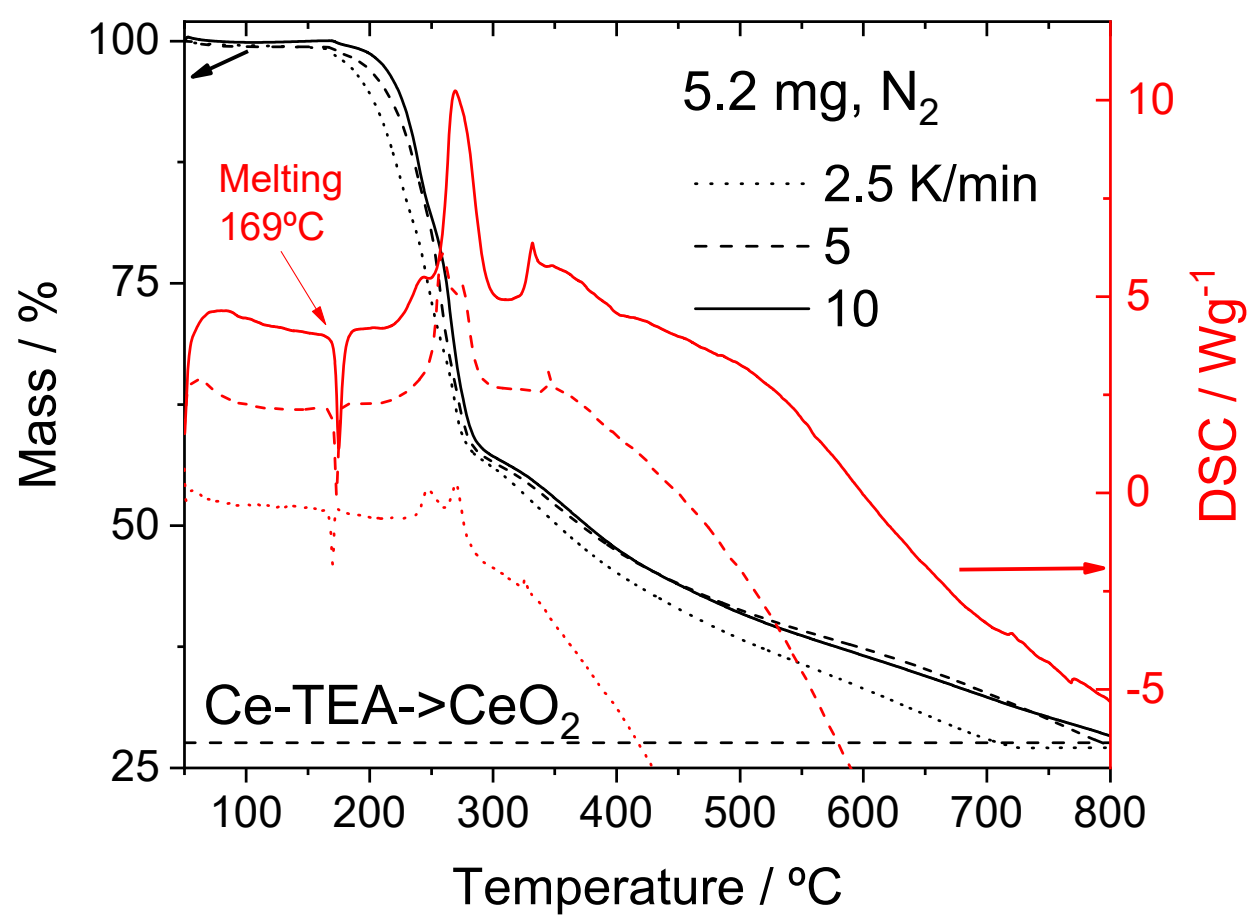

Fig. 1. Simultaneous TG-DSC analysis of complex Ce-TEA heated at 2.5, 5 and 10 $\mathrm{K} /$ min under flowing $\mathrm{N}_{2}$. A sample of mass $5.2 \mathrm{mg}$ is placed in a $150 \mu \mathrm{l}$ alumina crucible. Horizontal dashed line: expected mass for the conversion of $\left[\mathrm{Ce}\left(\mathrm{NO}_{3}\right)\left(\mathrm{C}_{6} \mathrm{H}_{15} \mathrm{NO}_{3}\right)_{2}\right]\left(\mathrm{NO}_{3}\right)_{2}$ into $\mathrm{CeO}_{2}$. 


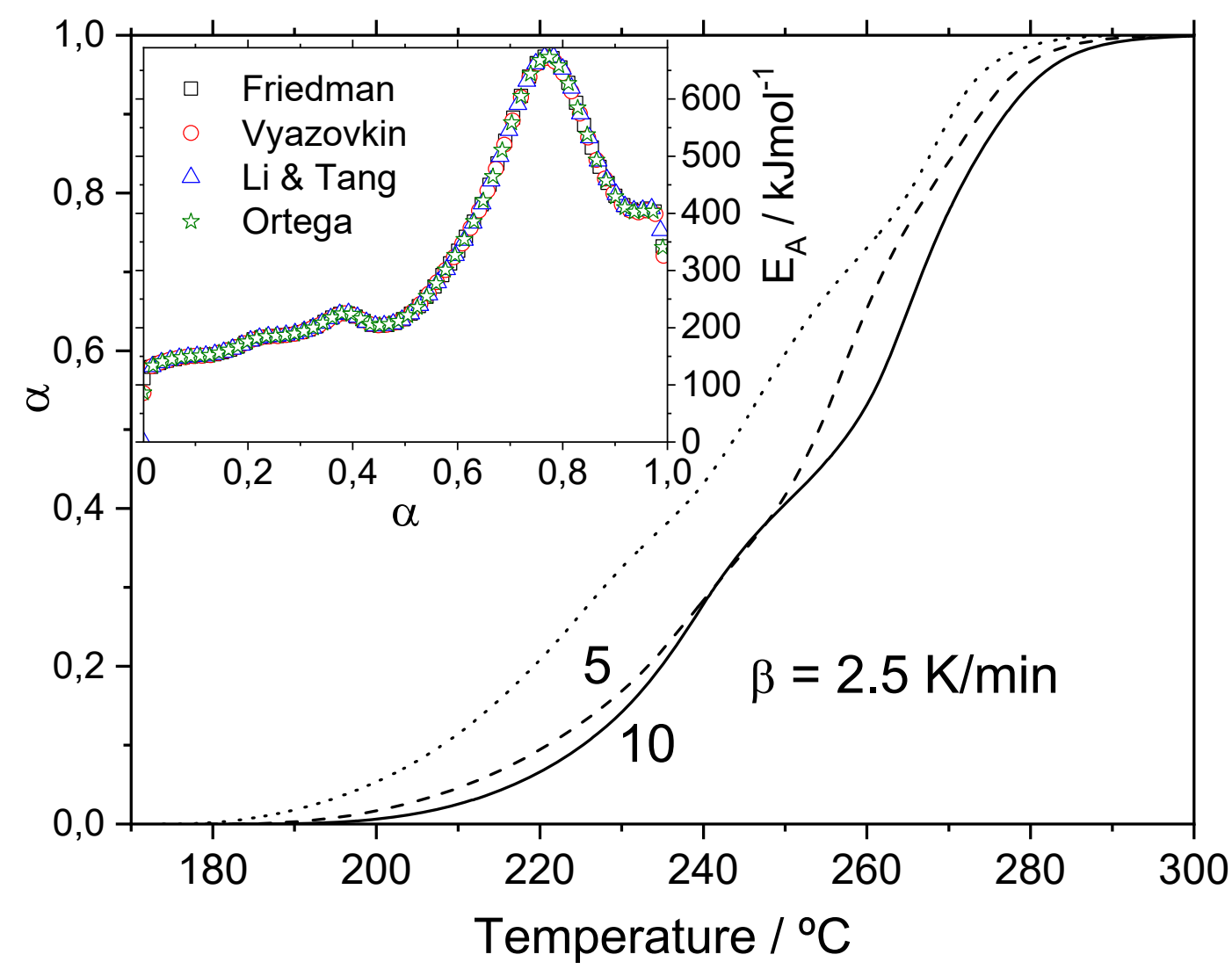

Fig. 2. Evolution of the transformed fraction extracted from Fig. 1. Inset: activation energy determined using different isoconversional methods. 


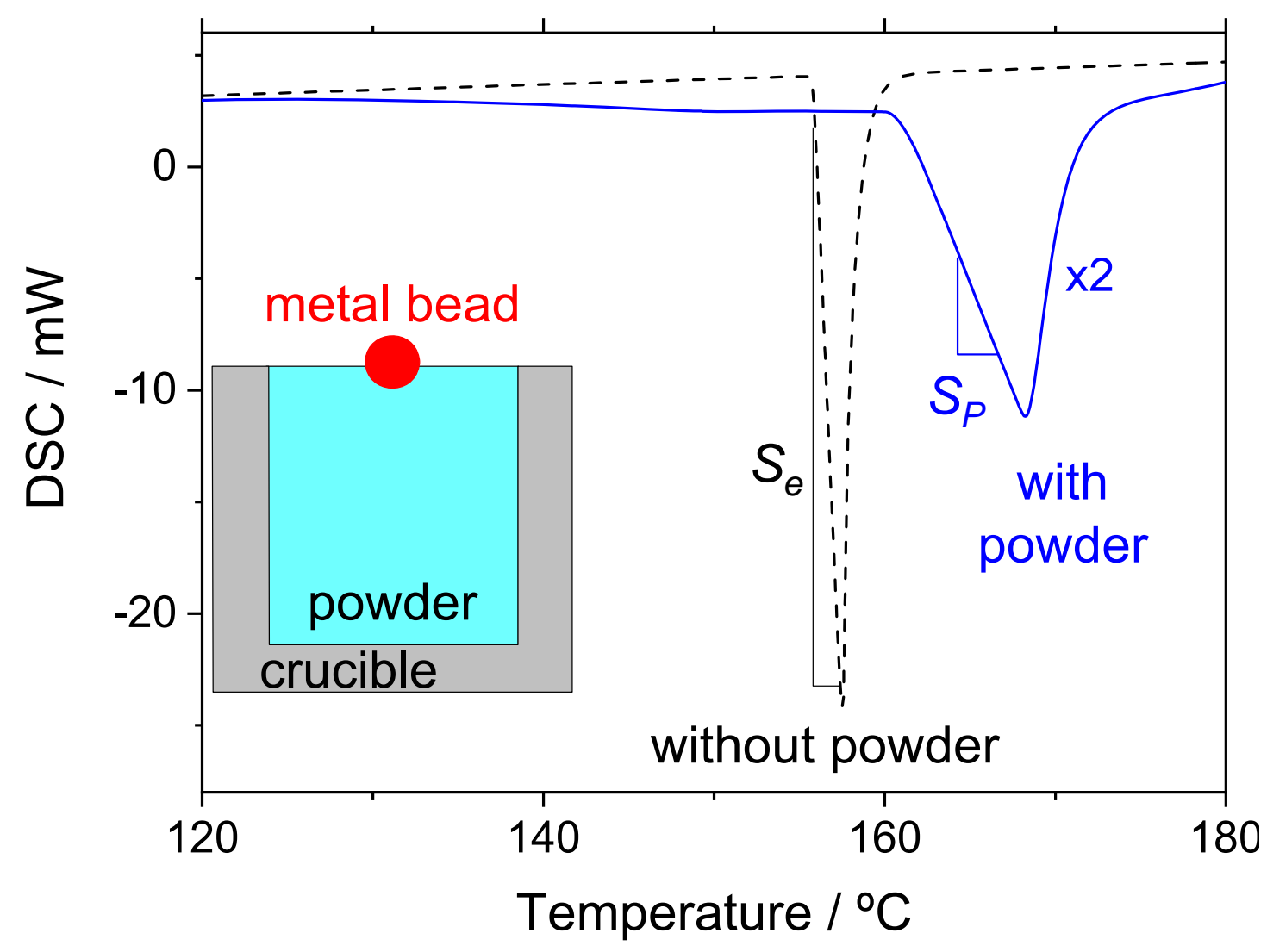

Fig. 3. DSC signal (with and without $\mathrm{Ce}-\mathrm{TEA}$ powders) with respect to temperature in a nitrogen flow. 


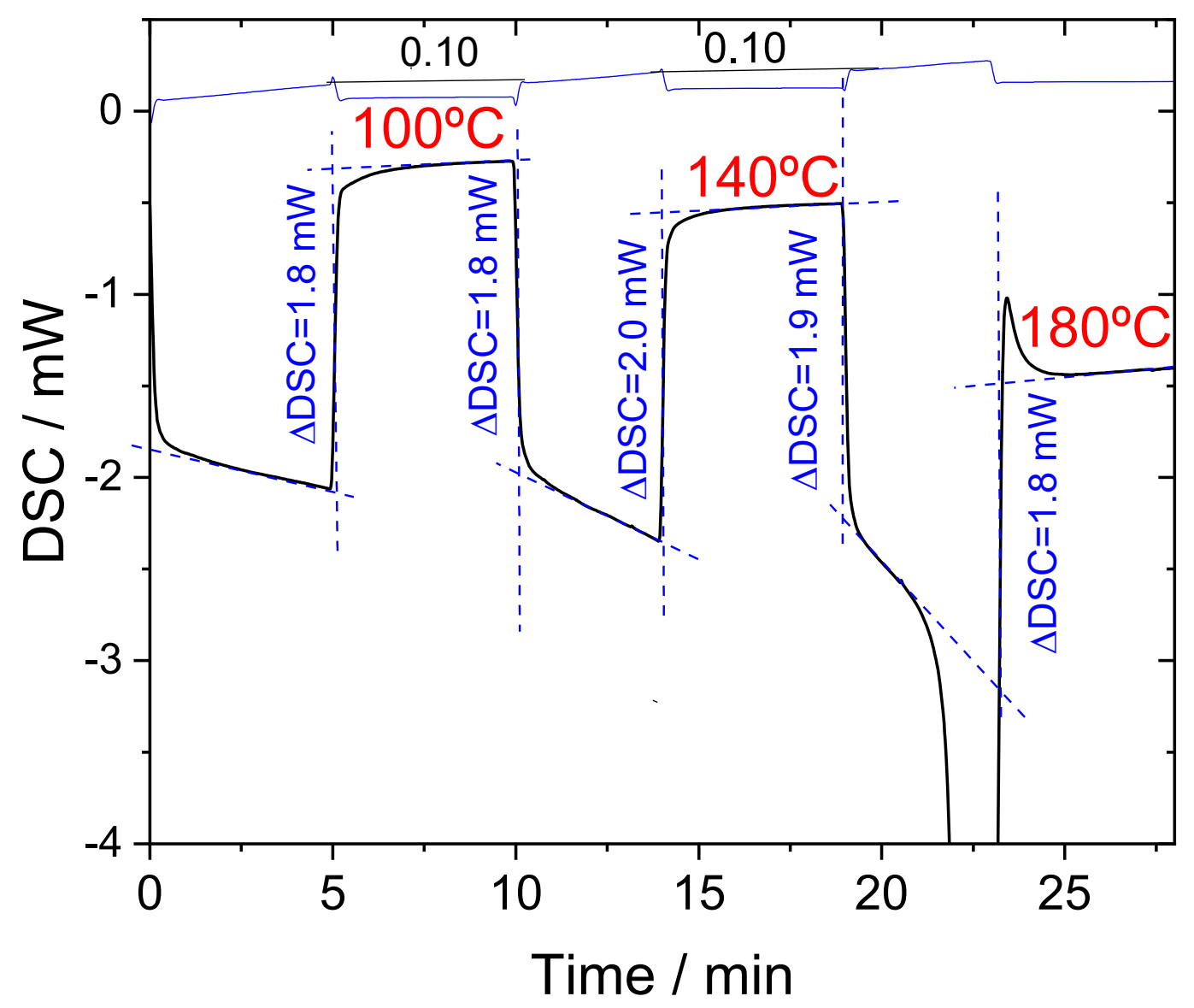

Fig. 4. Temperature program and DSC measurement of Ce-TEA powders used to determine the heat capacity. On the top the signal recorded when two empty crucibles are placed in the DSC. 


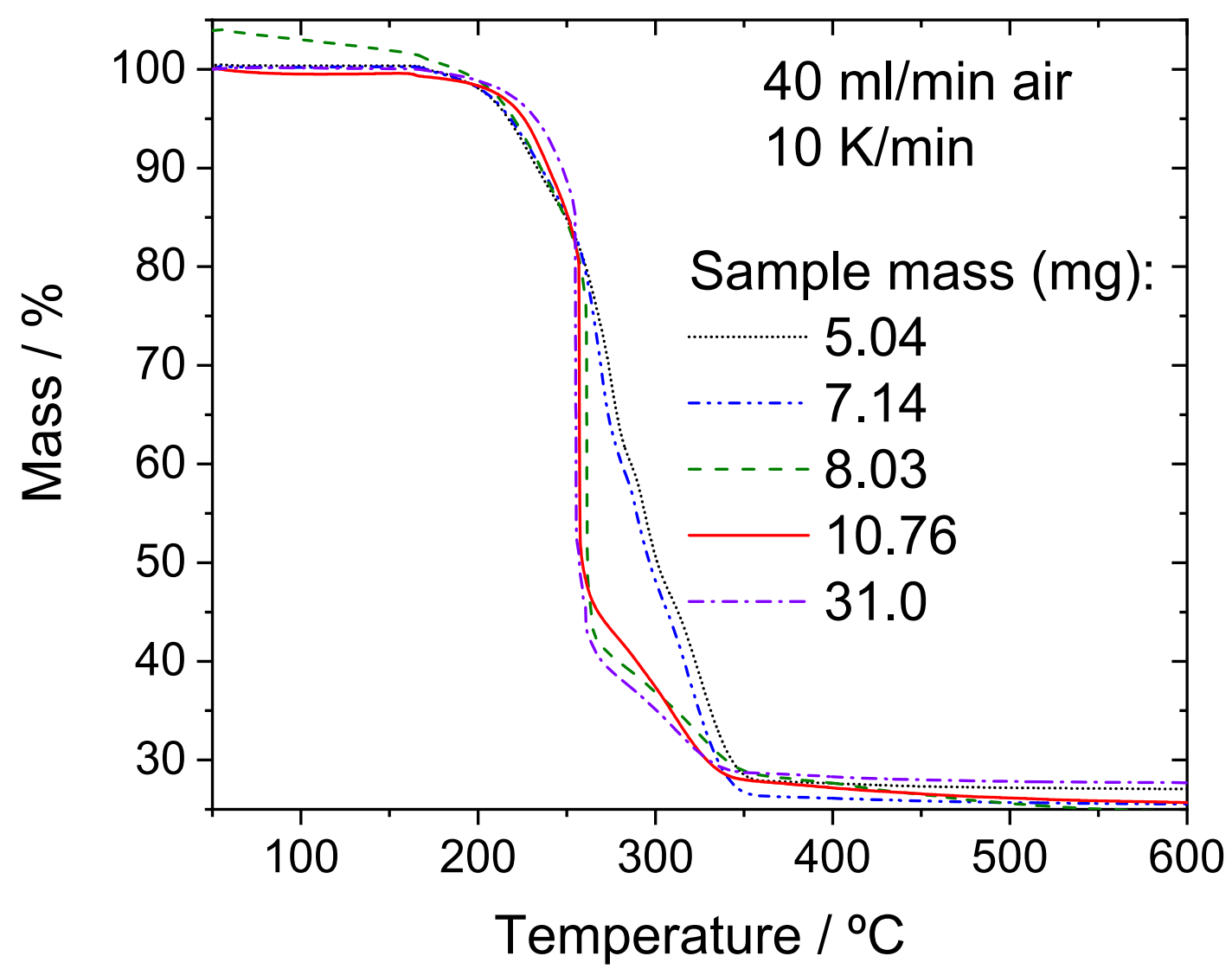

Fig. 5. TG analysis of complex Ce-TEA heated at $10 \mathrm{~K} / \mathrm{min}$ under flowing air for different sample masses. Samples are place in a $150 \mu 1$ alumina crucible. 


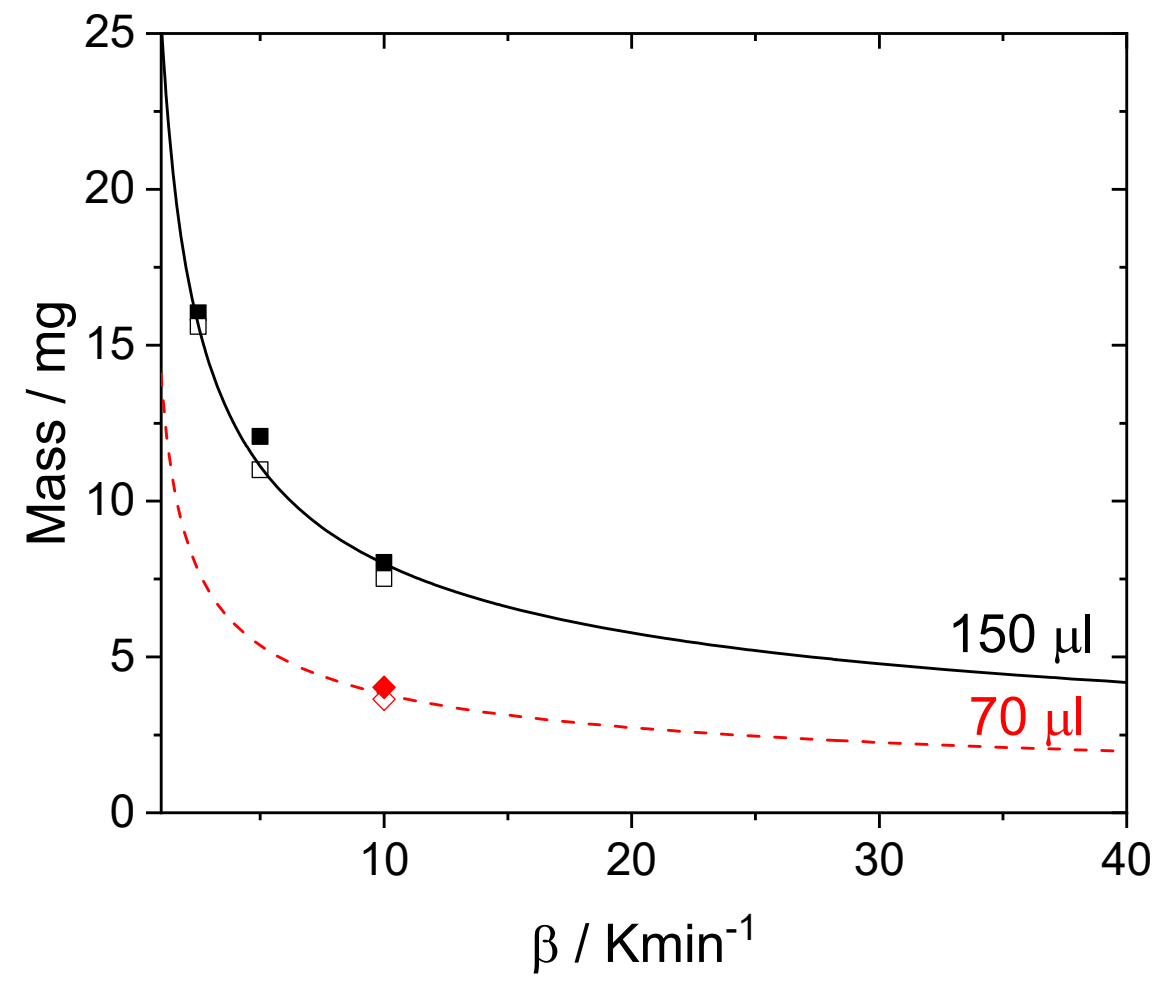

Fig. 6. Solid and dashed lines are the critical masses calculated using Eq. 12 for crucibles of volume $150 \mu 1$ and $70 \mu 1$ respectively. Symbols are determined from TG measurements like those of Fig. 5. Full symbols correspond to the smaller mass for which thermal explosion has been observed while empty symbols are related to the larger mass that does not undergo thermal explosion. Squares and stars correspond to experiments performed on crucible of volume $150 \mu 1$ and $70 \mu 1$ respectively. 